\title{
Abnormal magnetic behaviour of powder metallurgy austenitic stainless steels sintered in nitrogen
}

\author{
C. García, F. Martin *, Y. Blanco \\ Ingeniería de Materiales, E.T.S.I.I., Universidad de Valladolid, Paseo del Cauce s/n, 47011 Valladolid, Spain
}

\section{A R T I C L E I N F O}

\section{Article history:}

Received 12 March 2009

Received in revised form

14 May 2009

Available online 27 May 2009

Keywords:

Magnetic measurement

Powder metallurgy

Austenitic stainless steel

\begin{abstract}
A B S T R A C T
The magnetic response of AISI 304L and AISI 316L obtained through powder metallurgy and sintered in nitrogen were studied. AISI 304L sintered in nitrogen showed a ferromagnetic behaviour in as-sintered state while AISI 316L was paramagnetic. After solution annealing both were paramagnetic. Magnetic behaviour was analysed by using a vibrating sample magnetometer, a magnetic ferritscope and magnetic etching. A microstructural characterization was performed by means of optical metallography, X-ray diffraction, scanning electron microscopy (SEM) and energy dispersive analysis of X-rays (EDS). Some samples when needed were submitted to aged heat treatments at 675 and $875^{\circ} \mathrm{C}$ for $90 \mathrm{~min}, 4,6$, 8 or $48 \mathrm{~h}$. The main microstructural feature found was the presence of a lamellar constituent formed by nitride precipitates and an interlamellar matrix of austenite and/or ferrite. The abnormal magnetic response was explained based on this.
\end{abstract}

(c) 2009 Elsevier B.V. All rights reserved.

\section{Introduction}

The powder metallurgy (PM) technology provides a feasible and economic manufacturing process of austenitic stainless steel (SS) components with complex shape, good corrosion resistance and non-ferromagnetic behaviour and advantages such as good dimensional precision, high surface finish and good mechanical properties [1,2].

Using nitrogen as sintering atmosphere is a cheaper process than sintering in vacuum. Furthermore, nitrogen in solid solution improves mechanical properties and corrosion resistance of SS [3-7] and is a good austenite stabilizer, consequently, promotes paramagnetic properties.

It is known that the positive effect of $\mathrm{N}, \mathrm{Cr}$ and Mo on pitting resistance equivalent number (PREN number) but only if they are in solid solution and homogeneously distributed. Such improvement is related with the structure and composition of passive films $[8,9]$. However, nitrogen is exerting a deleterious effect on intergranular corrosion resistance when the solubility limit of nitrogen in austenite is exceeded. Precipitation of nitrogen compounds might cause chromium depletion and subsequent brittle mechanical behaviour and poor corrosion resistance.

The magnetic properties of austenitic SS have been scarcely investigated and even less for PM austenitic SS. Most of the

\footnotetext{
* Corresponding author. Postal address: Departamento CMeIM/EGI/ICGF/IM/IPF, EUP, Universidad de Valladolid, c/Francisco Mendizabal s/n, 47014 Valladolid, Spain. Tel.: +3498342 3515; fax: +34983184514.

E-mail address: fmp@eis.uva.es (F. Martin).
}

conventional austenitic SS are paramagnetic provided they show an austenitic microstructure. However this non-magnetic property declines when: (a) delta ferrite is retained during a rapid solidification process; (b) martensitic transformation occurs by several processes (cold working [10-13], wearing [14], irradiating with hydrogen ions [15] or reaching cryogenic temperatures [16]); (c) some secondary phases precipitation by heating (sensitization) [17,18]; (d) in high nitrogen-alloyed SS $[19,20]$ the expanded austenite is magnetic.

In this work, it has been found that PM AISI 304L and $316 \mathrm{~L}$ sintered in vacuum show the typical non-magnetic behaviour. PM 316L sintered in nitrogen also shows non-magnetic behaviour. However, PM 304L sintered in nitrogen is ferromagnetic. The materials were mainly investigated in as-sintered and solution annealing states but also, when necessary, some samples were submitted to ageing heat treatments. Such magnetism is tentatively explained in terms of chemical compositions and microstructural features mainly related to the cellular precipitation of nitride precipitates.

\section{Materials and methods}

Two pre-alloyed and water-atomized powders were used in this work, AISI 304L (0.009\% C, $0.78 \% \mathrm{Si}, 11.4 \% \mathrm{Ni}, 18.5 \% \mathrm{Cr}, 0.18 \% \mathrm{Mn}, \mathrm{Fe}$ bal.) with apparent density $2.88 \mathrm{~g} / \mathrm{cm}^{3}$ and AISI $316 \mathrm{~L}(0.021 \% \mathrm{C}$, $0.87 \% \mathrm{Si}, 0.20 \% \mathrm{Mn}, 16.1 \% \mathrm{Cr}, 13.55 \% \mathrm{Ni}, 2.24 \% \mathrm{Mo}, 0.02 \% \mathrm{Cu}$, Fe bal.) with apparent density $3.1 \mathrm{~g} / \mathrm{cm}^{3}$. Powder was compacted as disc specimen $(25 \mathrm{~mm}$ in diameter and $6 \mathrm{~mm}$ in height) at $750 \mathrm{MPa}$. 
Compaction was carried out with a floating die, using zinc stearate as die lubricant. Green compacts were sintered in $\mathrm{N}_{2}-\mathrm{H}_{2}$ (95-5\%) atmosphere at $1250{ }^{\circ} \mathrm{C}$ for $30 \mathrm{~min}$ and a cooling rate of $5{ }^{\circ} \mathrm{C} / \mathrm{min}$ (referred hereafter as "as-sintered 304L N or 316L N samples"). Some as-sintered 304L N and 316L N samples were annealed by heating at $1150^{\circ} \mathrm{C}$ for $60 \mathrm{~min}$ under a stream of argon before being water quenched ("annealed samples"). Some annealed samples were aged by heating at temperatures of 675 or $875^{\circ} \mathrm{C}$ under a stream of argon for $90 \mathrm{~min}, 4,6,8$ or $48 \mathrm{~h}$ and air cooled ("aged samples"). Some green compacts were sintered in vacuum and taken as reference for the magnetic and microstructural studies.

Magnetic behaviour was analysed by using a vibrating sample magnetometer, a magnetic ferritscope for evaluation of the volume fraction of magnetic content and a magnetic etching to determine the spatial distribution of ferromagnetic regions. Microstructural characterization was performed by optical metallography and scanning electron microscopy (SEM). Samples were polished and etched before observation. Several etchants were used depending on the feature of interest: oxalic acid electrolytic etch, Beraha's tint etch, $\mathrm{NaOH}$ electrolytic etch, aqua regia etch and Vilella's reagent. Furthermore, samples were analysed by X-ray diffraction (XRD) and energy dispersive analysis of X-rays (EDS) to help for the identification of different phases. Some bulk-extracted powders were analysed by XRD. Bulk extraction was performed by electrolytic dissolution of the matrix with $10 \% \mathrm{HCl}$ in methanol solution at 5-6V. Residues were filtered and XRD was performed to identify precipitated secondary phases.

\section{Results and discussion}

Microstructures of as-sintered 304L N and 316L N are shown in Fig. 1a and b. Austenitic grains with intense intergranular precipitates and a lamellar constituent were observed. The lamellar constituent was predominant for 304L N while for 316L $\mathrm{N}$ appeared thinner and in lower proportion. In regard to the lamellar constituent, it is generally assumed [4,21-26] to be formed by lamellae of nitride precipitate $\left(\mathrm{Cr}_{2} \mathrm{~N}\right)$ and an austenitic interlamellar matrix.

Annealing dissolved the lamellar constituent and an austenitic microstructure, free of precipitates, and similar to samples sintered in vacuum was observed (see Fig. 1c for 304L). The effect of subsequent aging was highly dependent on temperature-time parameters. For the lowest temperature-time condition, inter/transgranular chromium precipitates were observed. The volume fraction of precipitates increases with increase in temperature and time, and finally at $875^{\circ} \mathrm{C}$ and $48 \mathrm{~h}$ continuous precipitation changed to cellular or discontinuous precipitation (Fig. 1d).

Typically austenitic SS are non-magnetic materials. However, measurements from the ferritscope (Table 1) show an important magnetic volume fraction for as-sintered 304L $\mathrm{N}$. Furthermore, the two samples sintered in vacuum and assintered 316L N showed very much lower magnetic response that was consistent with their expected paramagnetic behaviour. This work is focused on trying to elucidate the cause of such behaviour which has not been reported before. It should be expected similar magnetic behaviour for both materials and atmospheres. However, such different magnetic behaviour must be caused by some facts related to chemical composition or microstructural features.

Global chemical composition or powder contamination cannot be the causes for the abnormal magnetism since 304L sintered in vacuum showed no ferromagnetism and the same powders were uses for both sintering atmospheres. The effect of the nitrogen arising from the sintering atmosphere must be the main cause of the abnormal magnetism. Aging heat treatment might give some helpful information. While heating the
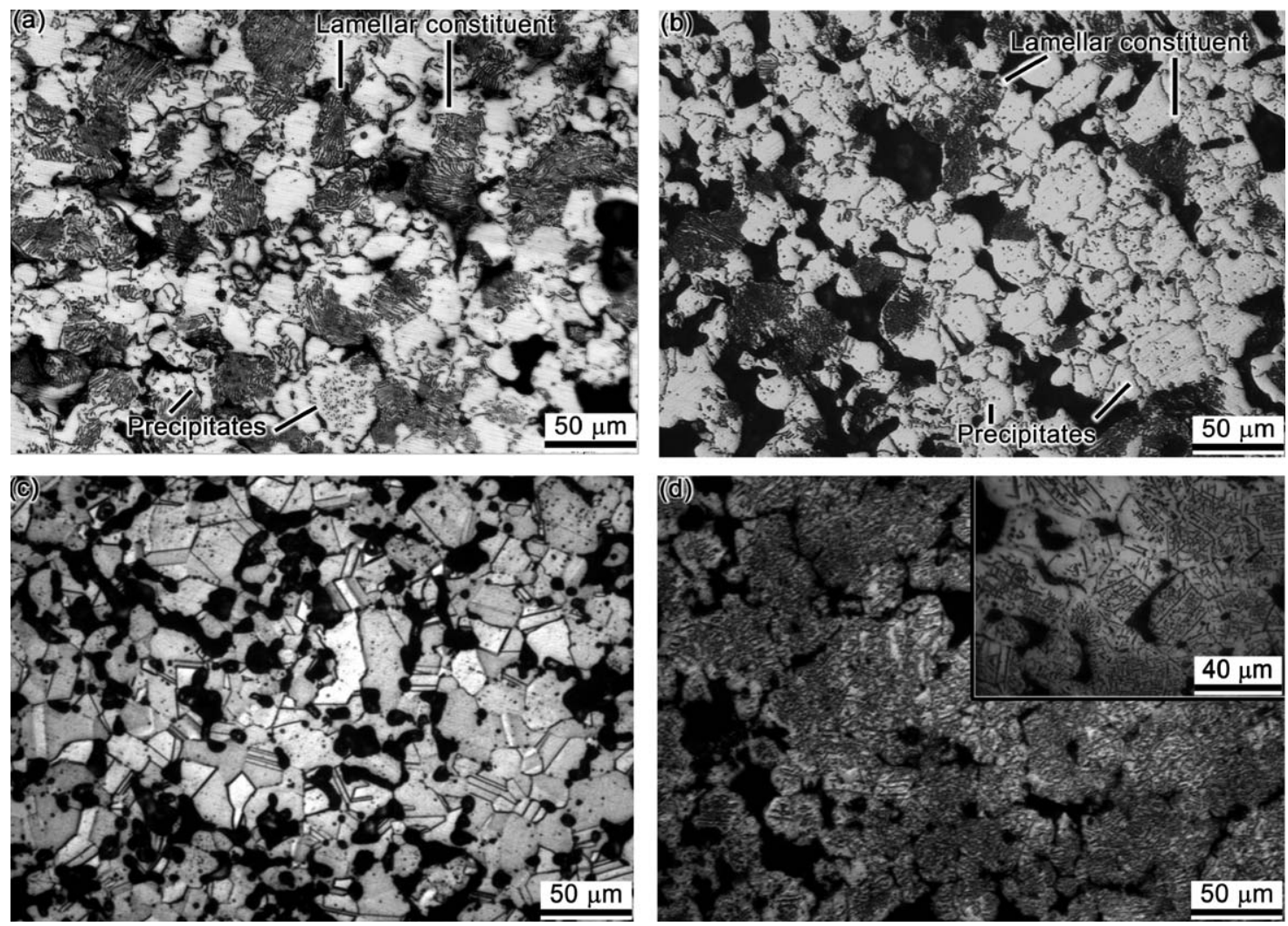

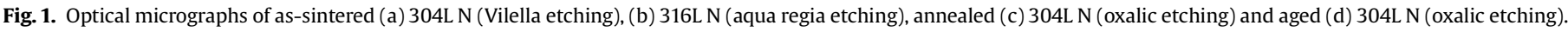


Table 1

Volume fraction of magnetic content of 304L and 316L measured by a ferritscope (in ferrite \%) for vacuum and nitrogen sintering atmospheres and several postsintering heat treatments (measuring accuracy: \pm 0.05 for $0-1 \%$ range, $\pm 0.15 \%$ for $0-3 \%$ range, $\pm 0.6 \%$ for $0-12 \%$ range and $\pm 2.5 \%$ for $0-50 \%$ range).

\begin{tabular}{|c|c|c|c|c|c|c|c|c|c|}
\hline & \multirow{3}{*}{$\begin{array}{l}\text { Vacuum } \\
\text { As-sintered }\end{array}$} & \multicolumn{8}{|l|}{$\mathrm{N}_{2}-\mathrm{H}_{2}$} \\
\hline & & \multirow[t]{2}{*}{ As-sintered } & \multirow[t]{2}{*}{ Annealed } & \multicolumn{3}{|c|}{$675^{\circ} \mathrm{C}$} & \multicolumn{3}{|c|}{$875^{\circ} \mathrm{C}$} \\
\hline & & & & $4 \mathrm{~h}$ & $8 \mathrm{~h}$ & $48 \mathrm{~h}$ & $4 \mathrm{~h}$ & $8 \mathrm{~h}$ & $48 \mathrm{~h}$ \\
\hline $304 \mathrm{~L}$ & 0.05 & 11.70 & 0.08 & 0.05 & 0.15 & 1.3 & 0.69 & 4.70 & 37.10 \\
\hline $316 \mathrm{~L}$ & 0.04 & 0.09 & 0.03 & 0.05 & 0.10 & 0.12 & 0.05 & 0.10 & 1.20 \\
\hline
\end{tabular}

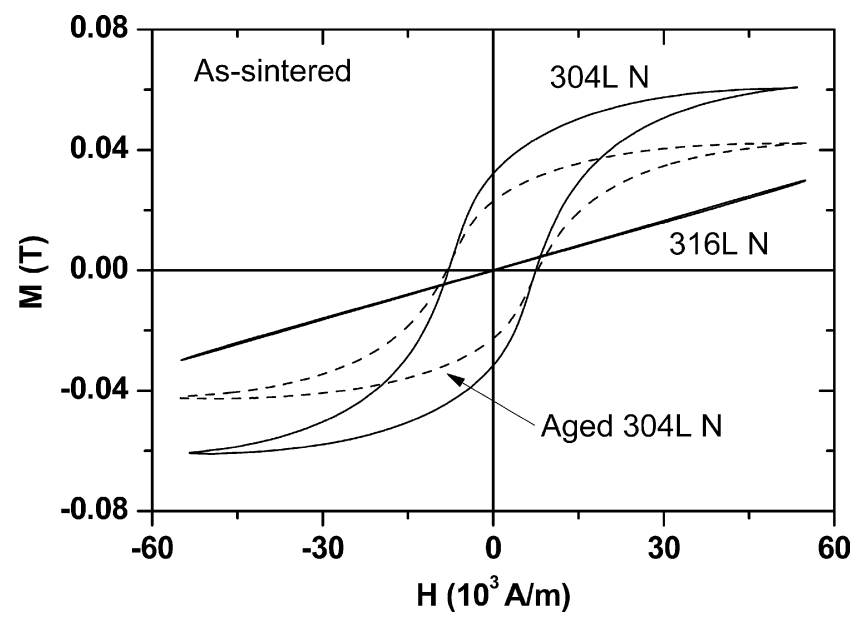

Fig. 2. Magnetisation vs. field dependence recorded at room temperature for assintered 304L N and 316L N and for aged $304 \mathrm{~L} \mathrm{~N}$ at $875^{\circ} \mathrm{C}$ for $8 \mathrm{~h}$. nitrogen-rich precipitates are formed and some increase in magnetic response is observed (Table 1). The 304L always shows higher response than 316L. Finally, the ferrite \% for 304L N aged at $875^{\circ} \mathrm{C}$ and $48 \mathrm{~h}$ was very much higher than any other state and material.

The magnetisation curve of as-sintered 304L $\mathrm{N}$ is shown in Fig. 2. A clear hysteresis loop was observed that was consistent with the ferritscope measurement. For 304L sintered in vacuum and annealed 304L $\mathrm{N}$ only the typical single line of paramagnetic materials was observed. The hysteresis loop again appeared on aged samples and showed that saturation magnetisation increased when temperature-time parameters increased. Furthermore, no hysteresis loop was observed for $316 \mathrm{~L}$ under any condition, either in as-sintered or annealed or aged states.

To elucidate which phase was ferromagnetic for 304L N, a magnetic etch was used. A previous conventional etching with aqua regia (3:3) was used to reveal the microstructure of the samples (Fig. 3a and b). Then a partial drop of magnetic colloid was dispensed on the sample surface. It was observed for as-sintered $304 \mathrm{~L} \mathrm{~N}$ that the colloid was strongly attracted on part of the lamellar constituent when the magnet was on (Fig. 3c). Some ferromagnetic contrast along grain boundaries was also detected. Therefore, the ferromagnetism is mainly associated to the lamellar constituent and in much lower intensity to the precipitates of the grain boundaries. The as-sintered $316 \mathrm{~L} \mathrm{~N}$ samples showed analogous behaviour but clearly with a very much lower contrast (Fig. 3d). These results are consistent with the magnetic response obtained from the ferritscope and the magnetomer measurements. It is relevant to notice that for $304 \mathrm{~L}$ $\mathrm{N}$ the magnetic colloid is not covering the whole lamellar constituent. It will be clear in what follows that the precipitates of the lamellae are of the same nature and, consequently, the
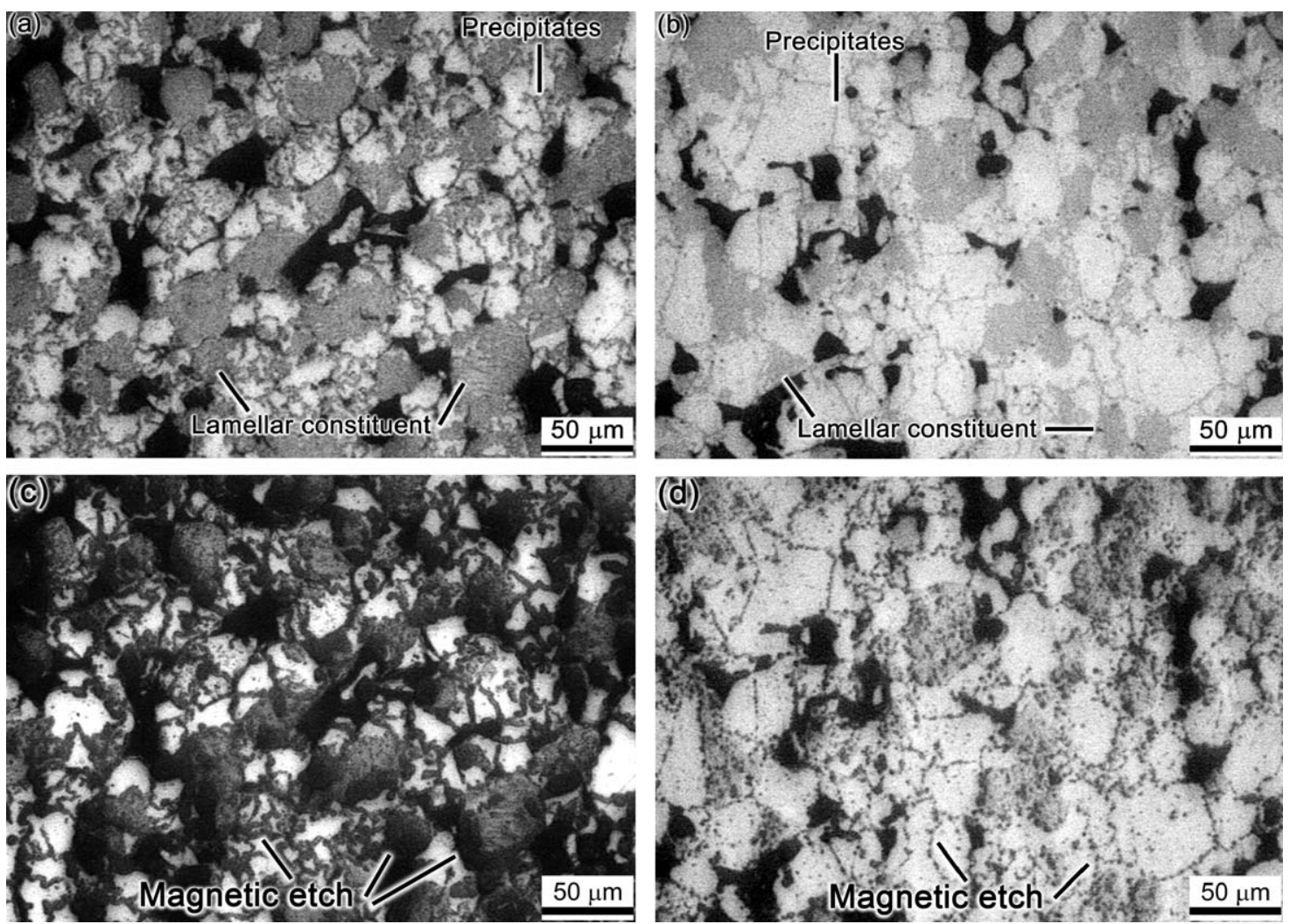

Fig. 3. Optical micrographs for magnetic etch. Magnet off: (a) 304L N and (b) 316L N and magnet on: (c) 304L N and (d) 316L N. 
nature of the matrix around precipitates will be the cause of such different magnetic behaviour.

The XRD diffractograms in Fig. 4a shows $\alpha$-peaks for assintered 304L $\mathrm{N}$ in addition to the expected intense $\gamma$-peaks of austenite and small and broads peaks assigned to nitrides/ carbides precipitates. These $\alpha$-peaks could either correspond to $\alpha$-ferrite or $\alpha^{\prime}$-martensite but XRD is not capable to resolve it. For as-sintered 316L N only the (110) $\alpha$-peak was detected. The peaks related to precipitates are not observed due to its very small amount. For annealed samples (Fig. 4a) only $\gamma$-peaks were observed. These clean diffractograms show that annealing treatment dissolved the $\alpha / \alpha^{\prime}$-phase and precipitates. Therefore, nitrogen dissolves forming expanded austenite. The possible denitrogenation [27] is not relevant as it is deduced from the analysis of aged samples where large amounts of nitride precipitates again appears. The XRD diffractograms of aged 304L $\mathrm{N}$ again show the peaks assigned to $\alpha / \alpha^{\prime}$-phase and precipitates (Fig. 4b). A quantitative analysis revealed that the amount of $\alpha / \alpha^{\prime}$-phase and nitride precipitates formed in 304L $\mathrm{N}$ was higher as aging temperature and time increases and, associated to this, a shift to higher diffraction angles was observed. It is remarkable

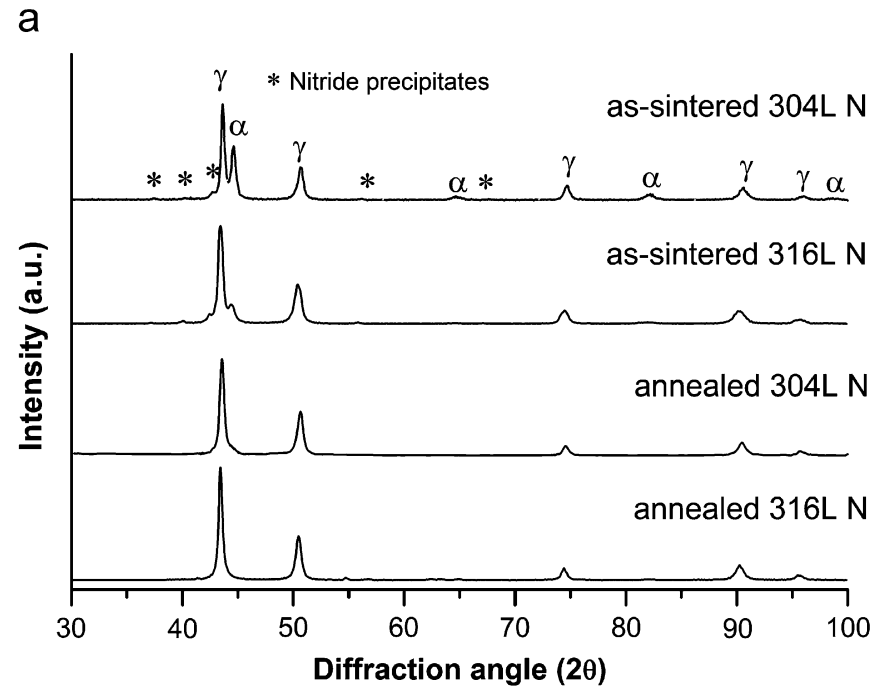

$\mathrm{b}$

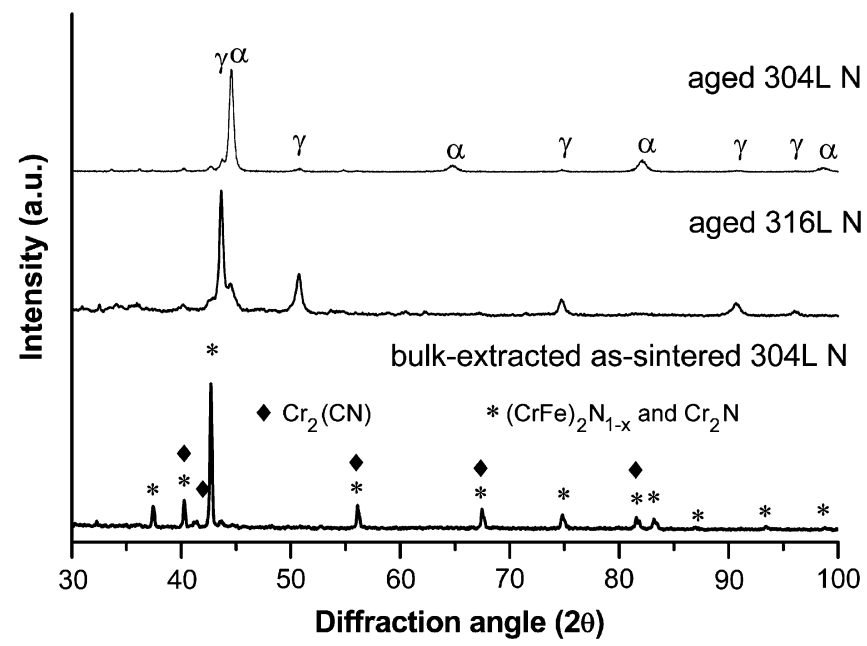

Fig. 4. X-ray diffractograms of (a) as-sintered 304L N and 316L N, annealed 304L N and $316 \mathrm{~L} \mathrm{~N}$, (b) aged $\left(875{ }^{\circ} \mathrm{C}\right.$ and $\left.48 \mathrm{~h}\right) 304 \mathrm{~L} \mathrm{~N}$ and $316 \mathrm{~L} \mathrm{~N}$ and bulk-extracted assintered 304L N. that the XRD diffractogram for $304 \mathrm{~L}$ aged at $875^{\circ} \mathrm{C}$ and $48 \mathrm{~h}$ (Fig. $4 \mathrm{~b}$ ) where $\alpha / \alpha^{\prime}$-peaks are much more intense than $\gamma$-peaks. This is consistent with the high registered magnetic response of this material, Table 1 . For aged 316L N only the (110) $\alpha$-peak was again detected (Fig. 4b).

The amount of precipitates in the samples is relatively small compared to bulk matrix so XRD analysis of bulk-extracted precipitates was required to identify these phases (Fig. 3). Chromium nitrides type $\mathrm{M}_{2} \mathrm{X}(\mathrm{M}=\mathrm{Cr}$, Mo $\mathrm{X}=\mathrm{N}, \mathrm{C})$ or chromium-iron nitrides type $(\mathrm{CrFe})_{x} \mathrm{X}_{1-x}$ were identified; the former was the main precipitated phase. The as-sintered and aged samples were containing small amounts of carbides, identified as type $\mathrm{M}_{7} \mathrm{C} 3$ or $\mathrm{M}_{6} \mathrm{C}$ rather than the typical $\mathrm{M}_{23} \mathrm{C}_{6}$. Very small content of intermetallic phases such as $\mathrm{Cr}-\mathrm{Ni}-\mathrm{Fe}, \sigma$-phase and Fe-Mn-Mo were also detected for 316L N.

The SEM micrographs show the same two basic constituents (lamellar and single phase with inter/transgranular precipitates) for both materials (Fig. 5). The lamellar constituent observed for 316L N was much finer than for 304L N. The morphology of the lamellar constituent identified as perlite-like colonies could be associated to the discontinuous or cellular precipitation observed in high nitrogen $\mathrm{Cr}-\mathrm{Ni}$ [28] and $\mathrm{Cr}-\mathrm{Mn}$ [29-31] stainless steels.

The EDS analysis of intergranular precipitates showed that $\mathrm{Cr}_{2} \mathrm{~N}$ was the main precipitate for $304 \mathrm{~L} \mathrm{~N}$ and $316 \mathrm{~L} \mathrm{~N}$ but for the latter additional phases of the type $\sigma$-Fe $\mathrm{Cr}$ Mo, $\mathrm{Cr}-\mathrm{Ni}-\mathrm{Fe}$, $\mathrm{Fe}-\mathrm{Mn}-\mathrm{Mo}$ and $(\mathrm{Cr}, \mathrm{Mo})_{2} \mathrm{CN}$ were also identified though in very small amount. The very small amount of transgranular precipitation was higher for $316 \mathrm{~L} \mathrm{~N}$, small precipitates with higher concentration of $\mathrm{Cr} / \mathrm{Mo}$ and specially $\mathrm{C}$ were observed and could be identified as the $\mathrm{M}_{6} \mathrm{C}$ and $\mathrm{M}_{7} \mathrm{C}_{3}$ phases detected by XRD. Single grains for $304 \mathrm{~L} \mathrm{~N}$ and $316 \mathrm{~L} \mathrm{~N}$ were identified as austenite from optical metallography, XRD and EDS analysis.

A full EDS analysis of the lamellar constituent was not possible due to its reduced thickness but it was clear that there were enrichment of $\mathrm{Cr}, \mathrm{C}$ and $\mathrm{N}$ compared to adjacent matrix. The EDS profile line results (Fig. 6) revealed that the lamellae should be nitrides and/or carbonitrides for 304L N and 316L N. Considering XRD results of bulk-extracted powders (Fig. 4b) the main precipitates must be $\mathrm{M}_{2} \mathrm{X}$ and $(\mathrm{Cr}, \mathrm{Fe})_{x} \mathrm{X}_{1-\mathrm{X}}(\mathrm{M}=\mathrm{Cr}$, Mo $\mathrm{X}=\mathrm{N}, \mathrm{C})$.

The precise analysis of the interlamellar matrices of $304 \mathrm{~L} \mathrm{~N}$ and $316 \mathrm{~L} \mathrm{~N}$ is not again possible due to its small thickness. However, lower concentration of $\mathrm{Cr}$ (10-14\%) and higher $\mathrm{Fe} / \mathrm{Mn}$ content than austenitic single grains for 304L N were observed. For 316L $\mathrm{N}$ a different conclusion was drawn. Its interlamellar matrix showed lower degree of chromium depletion than 304L N and higher amount of $\mathrm{Ni}$ and of course of Mo. Furthermore, the chemical analysis of the adjacent matrix (single grains) indicated contents of $\mathrm{Cr}$, Ni and Mo similar to those of the interlamellar matrix. Therefore, most probably, both phases were austenite which is paramagnetic.

Summarizing, the lamellar constituent is formed by lamellae, mainly of $\mathrm{Cr}_{2} \mathrm{~N}$, and an interlamellar matrix which is different for both materials. For 316L N such matrix is austenite but, for 304L $\mathrm{N}$, a ferromagnetic phase like $\alpha / \alpha^{\prime}$-phase due to its lower concentration of $\mathrm{Cr}$ must be present. A detailed observation of Fig. 3b compared to Fig. 3a shows that not all the lamellar constituent of 304L N is magnetically etched. Thus, some zones of the interlamellar matrix must show different chemical composition than the others.

As a suggestion, it is very probable that the lamellar constituent is formed by the discontinuous or cellular mechanism of precipitation found on some SS. In this way, the interlamellar matrix could be initially formed by supersaturated $\gamma_{\mathrm{N}}$-austenite which later, for $304 \mathrm{~L} \mathrm{~N}$, partially transformed into $\alpha / \alpha^{\prime}$-phase, as it has been reported for nitrided SS [20,32-35]. For 316L $N$ the higher content of $\mathrm{Cr}$, Ni and Mo could justify the absence of 

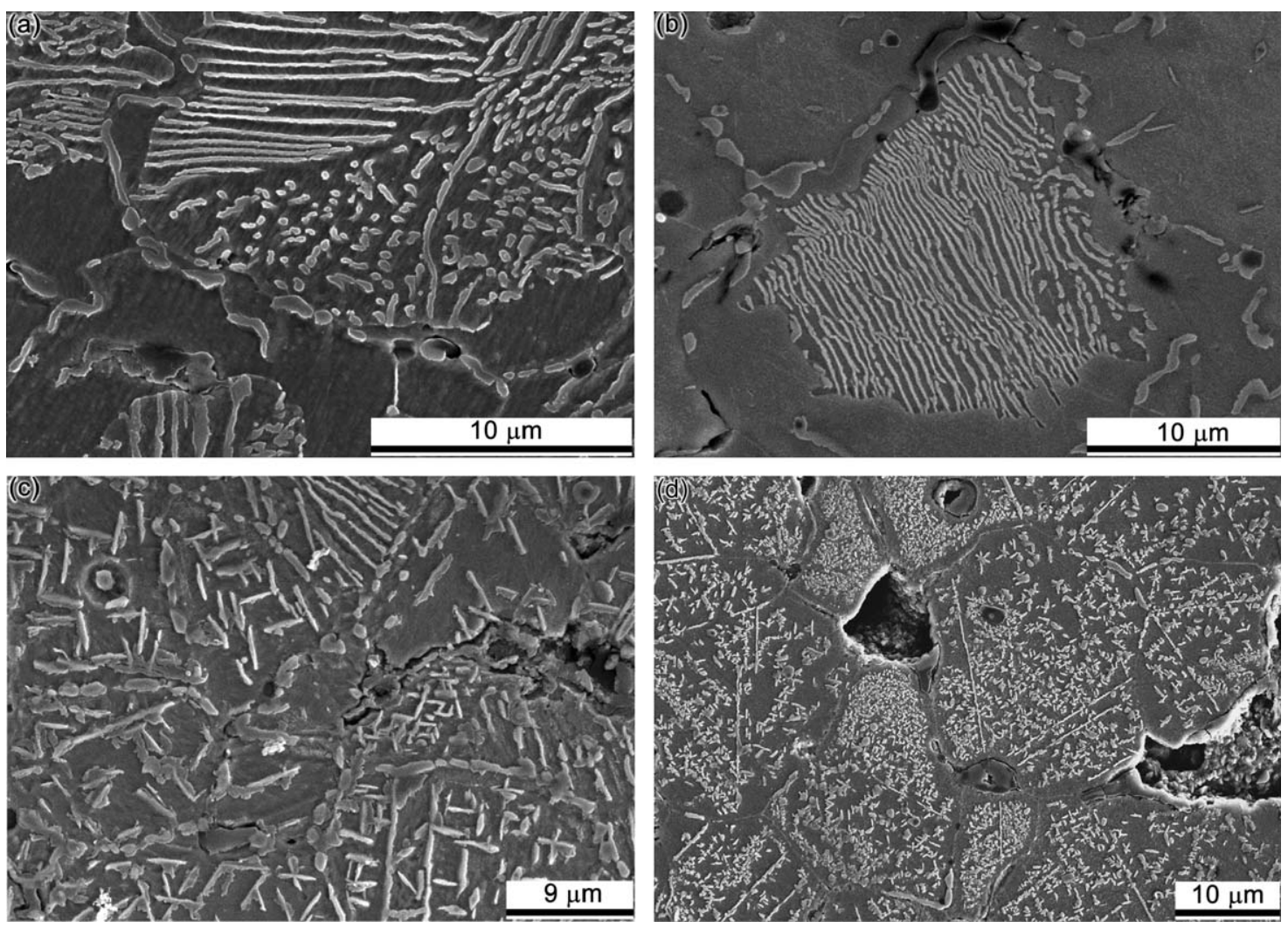

Fig. 5. SEM micrographs of (a) as-sintered $304 \mathrm{~L} \mathrm{~N}$ and (b) $316 \mathrm{~L} \mathrm{~N}$, (c) aged ( $875^{\circ} \mathrm{C}$ and $48 \mathrm{~h}$ ) $304 \mathrm{~L} \mathrm{~N}$ and (d) $316 \mathrm{~L} \mathrm{~N}$ (Vilella etching).

$\alpha / \alpha^{\prime}$-phase due to a much lower martensitic transformation temperature. The transformation of $\gamma_{\mathrm{N}}$-austenite to ferromagnetic martensite after sensitisation when $\mathrm{Cr}$ content decreased to about $10 \%$ [36-41] also supports this hypothesis. Therefore, the main conclusion of this analysis is that the interlamellar matrix is the main cause of the different magnetic behaviour and it is due to a different chemical composition. Such different chemical composition is caused by the amount of precipitates and its distribution in such way that for $304 \mathrm{~L} \mathrm{~N}$ the amount of mainly $\mathrm{Cr}$ in the interlamellar matrix is low enough.

The SEM/EDS study of aged samples revealed that the precipitation process is complex (Fig. 5c and d). First, intergranular precipitation takes place and only when grain boundaries were completed it was observed transgranular precipitation. After a certain time the transgranular and orientated needle-like precipitates were observed, also rod-shaped precipitates appeared. The cellular precipitation started from grain boundaries and the volume fraction increased with increasing aging time but, in every case, in lower amount than for as-sintered samples. The chromium depleted matrix detected for aged 304L N as a consequence of this complex precipitation process could explain the magnetic response showed by aging samples (Fig. 6b). This means that the diffusion of $\mathrm{Cr}$ to the nitride precipitates promotes a lower enough content of $\mathrm{Cr}$ to allow the formation of the ferromagnetic $\alpha^{\prime}$-phase. The lower amount of precipitation of $316 \mathrm{~L} N$ could partially explain its different magnetic behaviour. The higher stability of austenite phase for 316L N (higher Ni and Mo) in regards to martensitic transformation could be "inhibited". This same behaviour has been observed elsewhere [36] for 316L SS after sensitization heat treatment.

The magnetic behaviour here described cannot be explained by the typical ferromagnetic transformations of SS as indicated in the introduction section. In effect, delta ferrite is not present in the samples and cannot be formed since sintering is not a rapid cooling process. Thermal martensite formation is discarded since martensitic transformation temperature is clearly below room temperature. Strain-induced martensite cannot be the cause of ferromagnetism. First, there is no cold working process and, second, if assisted stress martensite is considered it would be maximum for $\gamma_{\mathrm{N}}$, i.e., in annealing state. The expanded austenite $\gamma_{\mathrm{N}}$ which in some studies is considered magnetic is here paramagnetic since the annealed samples show very low magnetic response. Finally, magnetism of secondary phases are also discarded as the cause of magnetism since they are present in both, the ferromagnetic 304L N and paramagnetic 316L N.

\section{Conclusion}

In conclusion, the present study shows the ferromagnetic behaviour of type 304L SS sintered in nitrogen in as-sintered and aged conditions. This has been justified in terms of nitride precipitation that might cause enough chromium depletion to favour ferromagnetic $\alpha^{\prime}$-phase formation. Therefore, the discontinuous or cellular precipitation of chromium nitrides can promote the magnetic response of $304 \mathrm{~L} \mathrm{~N}$. Such phenomenon has not been observed in samples sintered in vacuum, which is consistent with the results shown. The 316L samples do not show ferromagnetic behaviour in any state. In as-sintered state, with the presence of lamellar constituent and precipitates, its magnetic behaviour is similar to the annealed state where a clean austenite is observed. Finally, in aged states where the amount of precipitates is progressively increasing with temperature-time parameters again no ferromagnetic response is observed. 

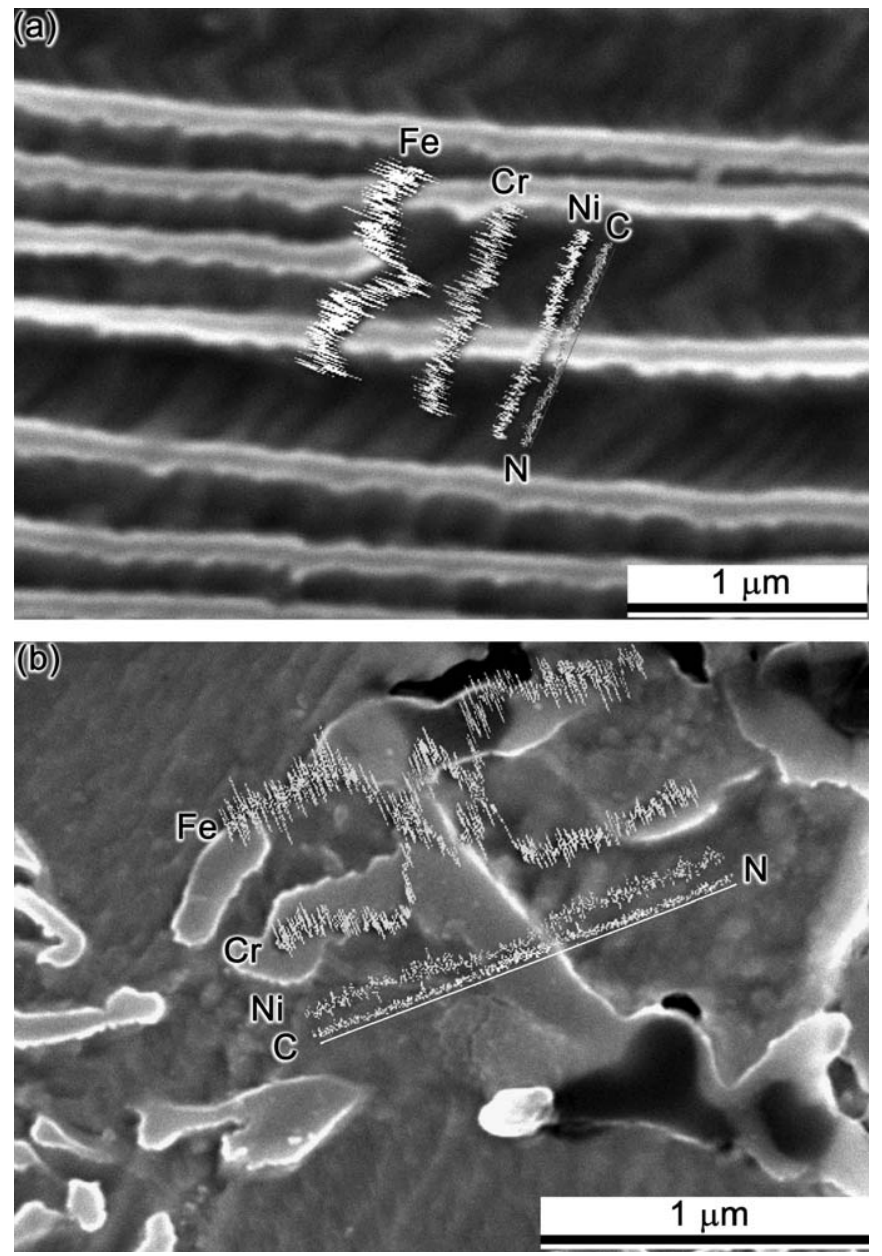

Fig. 6. EDS line profile of (a) lamellar constituent of as-sintered 304L N and (b) precipitate of as-sintered 304L N.

\section{Acknowledgment}

Financial support from Dirección General de Programas y Transferencia de Conocimiento, Ministerio de Ciencia e Innovación, Spain, reference MAT2008-02788 is gratefully acknowledged.

\section{References}

[1] P. Lindskog, The future of ferrous PM in Europe, Powder Metall. 47 (2004) 6-9.

[2] E. Klar, P.K. Samal, Powder Metallurgy Stainless Steels: Processing, Microstructures, and Properties, ASM, Materials Park, OH, 2007.

[3] H. Hännimen, J. Romu, R. Ilda, J. Tervo, A. Laitinen, Effects of processing and manufacturing of high nitrogen-containing stainless steels on their mechanical, corrosion and wear properties, J. Mater. Process. Technol. 117 (2001) 424-430.

[4] C. García, F. Martin, P. de Tiedra, L. García Cambronero, Pitting corrosion behaviour of PM austenitic stainless steels sintered in nitrogen-hydrogen atmosphere, Corros. Sci. 49 (2007) 1718-1736.

[5] C. García, F. Martin, P. de Tiedra, Y. Blanco, J.M. Ruiz Roman, M. Aparicio, Electrochemical reactivation methods applied to PM austenitic stainless steels sintered in nitrogen-hydrogen atmosphere, Corros. Sci. 50 (2008) 687-697.

[6] F. Martin, C. García, P. de Tiedra, Y. Blanco, M.L. Aparicio, Sensitization of powder metallurgy type 430L stainless steel sintered in nitrogen-hydrogen atmosphere, Corrosion 64 (2008) 70-82.

[7] T. Lee, C. Oh, S. Kim, Effects of nitrogen on deformation-induced martensitic transformation in metastable austenitic Fe- $18 \mathrm{Cr}-10 \mathrm{Mn}-\mathrm{N}$ steels, Scr. Mater. 58 (2008) 110-113.

[8] A. Igual Muñoz, J. García Antón, S. Lópex Nuévalos, J.L. Guiñón, V. Pérez Herranz, Corrosion studies of austenitic and duplex stainless steels in aqueous lithium bromide solution at different temperatures, Corros. Sci. 46 (2004) 2955-2974
[9] Z. Cvijovic, G. Radenkovic, Microstructure and pitting corrosion resistance of annealed duplex stainless steel, Corros. Sci. 48 (2006) 2887-3906.

[10] L. Zhang, S. Takashi, Y. Kamada, Quench-induced martensitic transformation in austenitic stainless steel after tensile deformation at elevated temperature, Scr. Mater. 57 (2007) 711-714.

[11] S.M. Tavares, M.R. da Silva, J.M. Neto, S. Miraglia, D. Fruchart, Ferromagnetic properties of cold rolled AISI 304L steel, J. Magn. Magn. Mater. 242 (2002) 1391-1394.

[12] K. Mumtaz, S. Takahashi, J. Echigoya, L. Zhang, Y. Kamada, M. Sato, Temperature dependence of martensitic transformation in austenitic stainless steel, J. Mater. Sci. Lett. 22 (2003) 423-427.

[13] K. Mumtaz, S. Takahashi, J. Echigoya, L. Zhang, H. Kikuchi, M. Sato, Magnetic measurements of martensitic transformation in austenitic stainless steel after room temperature rolling, J. Mater. Sci. 39 (2004) 85-97.

[14] M. Zandrahimi, M. Reza, A. Poladi, J.A. Szpunar, The formation of martensite during wear of AISI 304 stainless steel, Wear 263 (2007) 674-678.

[15] W. Hübner, A. Pyzalla, K. Assmus, E. Wild, T. Wroblewski, Phase stability of AISI 304 stainless steel during sliding wear at extremely low temperatures, Wear 255 (2003) 476-480.

[16] Z.Z. Yuan, Q.X. Dai, Q. Zhang, X.N. Cheng, K.M. Chen, Effects of temperature cycling and nitrogen on the stability of microstructures in austenitic stainless steels, Mater. Charact. 59 (2008) 18-22.

[17] Y. Kamada, T. Mikami, S. Takahashi, H. Kikuchi, S. Kobayashi, K. Ara, Compositional dependence of magnetic properties on thermally sensitized austenitic stainless steels, J. Magn. Magn. Mater. 310 (2007) 2856-2858.

[18] S. Takahashi, Y. Sato, Y. Kamada, T. Abe, Study of chromium depletion by magnetic method in Ni-based alloys, J. Magn. Magn. Mater. 269 (2004) 139-149.

[19] M.P. Fewell, D.R.G. Mitchell, J.M. Priest, K.T. Short, G.A. Collins, The nature of expanded austenite, Surf. Coat. Technol. 131 (2000) 300-306.

[20] O. Öztürk, D.L. Williamson, Surf. Coat. Technol. 158-159 (2002) 288

[21] C. García, F. Martin, Y. Blanco, M.P. de Tiedra, M.L. Aparicio, Influence of sintering under nitrogen atmosphere on microstructures of powder metallurgy duplex stainless steels, Metall. Mater. Trans. A 40 (2009) 292-301.

[22] P. Shankar, H. Shaikh, S. Sivakumar, S. Venugopal, D. Sundararaman, H.S Khatak, Effect of thermal aging on the room temperature tensile properties of AISI type 316LN stainless steel, J. Nucl. Mater. 264 (1999) 29-34.

[23] W.A. Soffa, Structures Resulting from Precipitation from Solid Solution, SS Handbook, Ninth ed., ASM, Ohio, 2000.

[24] M. Kikuchi, T. Urabe, G. Cliff, G.W. Lorimer, The loss of driving force due to volume diffusion ahead of a migrating boundary in a cellular precipitation reaction, Acta Metall. Mater. 38 (1990) 1115-1120.

[25] N.C.S. Srinivas, V.V. Kutumbarao, On the discontinuous precipitation of $\mathrm{Cr}_{2} \mathrm{~N}$ in Cr-Mn-N austenitic stainless steels, Scr. Mater. 37 (1997) 285-291.

[26] F. Vanderschaeve, R. Taillard, J. Foct, Discontinuous precipitation of $\mathrm{Cr}_{2} \mathrm{~N}$ in a high nitrogen, chromium-manganese austenitic stainless steel, J. Mater. Sci. 30 (1995) 6035-6046.

[27] L.M. Kaputkina, A.G. Svyazhin, V.G. Prokoshkina, Dissolution and precipitation of excess phases and the nitrogen distribution between a solid solution and nitrides in a corrosion-resistant steel, Russ. Metall. 5 (2006) 439-444.

[28] M. Kikuchi, M. Kajihara, S.K. Choi, Cellular precipitation involving both substitutional and interstitial solutes-cellular precipitation of $\mathrm{Cr}_{2} \mathrm{~N}$ in $\mathrm{Cr}-\mathrm{Ni}$ austenitic steels, Mater. Sci. Eng. A 146 (1991) 131-150

[29] R.D. Knutsen, C.I. Lang, J.A. Basson, Discontinuous cellular precipitation in a $\mathrm{Cr}-\mathrm{Mn}-\mathrm{N}$ steel with niobium and vanadium additions, Acta Mater. 52 (2004) 2407-2417.

[30] N.C.S. Srinivas, V.V. Kutumbarao, Growth mechanism for discontinuous precipitation in a multi-component ( $\mathrm{Fe}-\mathrm{Cr}-\mathrm{Mn}-\mathrm{N})$ system, Scr. Mater. 51 (2004) 1105-1109.

[31] M.E. Rodriguez-Castillo, V.M. Lopez-Hirata, M.L. Saucedo-Muñoz, H.J. Dorantes-Rosales, Kinetics of cellular precipitation in a $24 \mathrm{Cr}-15 \mathrm{Ni}-4 \mathrm{Mn}-$ 0.03C-0.35N steel, J. Mater. Sci. 39 (2004) 5537.

[32] C. Blawert, B.L. Mordike, Y. Jiraskova, O. Schneeweiss, Structure and composition of expanded austenite produced by nitrogen plasma immersion ion implantation of stainless steels X6CrNiTi1810 and X2CrNiMoN2253, Surf. Coat. Technol. 116 (1999) 189-198.

[33] D. Müller, G.K. Wolf, B. Stahl, L. Amaral, M. Behar, J.B.M. da Cunha, Phase transformation and corrosion behavior of stainless steel bombarded by pulsed energetic ion beams, Surf. Coat. Technol. 158-159 (2002) 604.

[34] X.L. Xu, L. Wang, Z.W. Yu, Z.K. Hei, Microstructural characterization of plasma nitrided austenitic stainless steel, Surf. Coat. Technol. 132 (2000) 270-274.

[35] Y. Ustinovshikov, A. Ruts, O. Bannykh, V. Blinov, M. Kostina, Microstructure and properties of the high-nitrogen $\mathrm{Fe}-\mathrm{Cr}$ austenite, Mater. Sci. Eng. A 262 (1999) 82-87.

[36] Y. Kamada, T. Mikami, S. Takahashi, H. Kikuchi, S. Kobayashi, K. Ara Compositional dependence of magnetic properties on thermally sensitized austenitic stainless steels, J. Magn. Magn. Mater. 310 (2007) 2856-2858.

[37] J. Manjanna, S. Kobayashi, Y. Kamada, S. Takahashi, H. Kikuchi, Martensitic transformation in SUS 316LN austenitic stainless steel at RT, J. Mater. Sci. 43 (2008) 2659-2665.

[38] M.K. Lei, Y. Huang, Z.L. Zhang, In situ transformation of nitrogen-induced HCP martensite in plasma source ion-nitrided austenitic stainless steel, J. Mater. Sci. Lett. 17 (1998) 1165-1167. 
[39] E.A. Trillo, R. Beltrán, J.G. Maldonado, R.J. Romero, L.E. Murr, W.W. Fisher, A.H. Advani, combined effects of deformation (strain and strain state), grain-size, and carbon content on carbide precipitation and corrosion sensitization in 304-stainless-steel, Mater. Charact. 35 (1995) 99-112.
[40] Y.J. Oh, J.H. Hong, Nitrogen effect on precipitation and sensitization in coldworked type 316L(N) stainless steels, J. Nucl. Mater. 278 (2000) 242-250.

[41] S. Takaya, T. Suzuki, Y. Matsumoto, K. Demachi, M. Uesaka, Estimation of stress corrosion cracking sensitivity of type 304 stainless steel by magnetic force microscope, J. Nucl. Mater. 327 (2004) 19-26. 